\title{
INNOVATIVE MANAGEMENT MODELS, EXAMPLES OF THREE COMPANIES
}

\author{
[Inovativní manažerské modely, př́íklad tří organizací]
}

\author{
Ludmila Mládková ${ }^{1}$ \\ ${ }^{1}$ Prague University of Economics and Business, Faculty of Business Administration, W. Churchilla 4, 13000 \\ Prague 3 \\ Email:mladkova@vse.cz
}

\begin{abstract}
In today's volatile environment, organizations have to address three new trends: they must be able to respond quickly to technological changes and increased information flows, they face the growth of knowledge work, and call for personal meaning. Some organizations try to achieve this with innovative management models. The management model is the way how managers execute their work in an organization. The paper focuses on three different innovative management models (W. L. Gore \& Associates, Zappos, and Spotify). The paper introduces them, discusses their similarities, and explores whether organizations use their models successfully or no.
\end{abstract}

Keywords: holacracy, lattice organization, management model, Spotify model.

JEL classification: M10

Received: 17.12.2020; Reviewed: 19.1.2021; 20.1.2021; 22.2.2021; Accepted: 19.5.2021

\section{Introduction}

The $21^{\text {st }}$ century challenges organizations with high speed of changes, information overload, global and local instabilities, demanding customers, and fierce competition. Lee and Edmondson (2017) classify these trends into three groups. The first group is fast information flows and sudden technological developments. When environments or customer needs change quickly, organizational employees may need to respond more quickly than managerial controls and reporting relationships allow, leading to missed opportunities and other failures (Lee and Edmondson 2017). The second group is the growth in knowledge-based work. When knowledge is a primary source of value creation, managers rarely have the full expertise needed to solve organizational problems. Instead, "individuals at all organizational levels must contribute information and ideas for their organizations to succeed" (Lee and Edmondson 2017, p. 37). Answers handed down from above are less likely to generate the products, services, or solutions needed to succeed. The third group is new trends towards viewing the work and organization "as places for personal meaning, given that some traditional sources of meaning play a declining role in many parts of society" (Lee and Edmondson 2017).

Organizations can succeed in such an environment only when deciding on the suitable business model (what to do) and deciding on the suitable management model (how to do it). Literature shows that organizations try to respond to trends classified by Lee and Edmondson (2017) by specific innovative management models.

The objective of this paper is to provide examples and discuss the potential of three innovative management models. Out of many different approaches, we chose revolutionary management models of W. L. Gore \& Associates, Zappos, and Spotify. The paper introduces them and provides their analysis. Finally, the models are compared to determine if there is something similar in how they work or are implemented. These similarities provide important knowledge on the strengths, limits, and applicability of innovative management models. 


\section{Methodology}

Organizations were chosen from the pool of organizations with unusual and innovative management models. We evaluated organizations on four parameters. First, we chose only globally known organizations; second, organizations are from various fields; third, the management model had to be specific, different from management models of other organizations; and fourth, the organization had to be the pioneer with the model, not the follower. E.g., we were searching for organizations whose management model is really innovative and unusual. The final decision which organization to analyze was made due to following reasons. W. L. Gore \& Associates attracted our attention as their management model was described as sustainable in the long term. The model is based on the same values and premises since the company's foundation in 1958, which is unique even among organizations with innovative models. We found Zappos management model based on sociocracy interesting as it works on rules very unusual in a business environment. Spotify was chosen as an example of organization whose unique innovative management model was presented as the model copied by other companies and the reason why the company is so successful.

It is necessary to stress that we chose organizations before a deep analysis of literature on them. We expected that all organizations successfully use their models at the moment of choice.

The data used in this paper are secondary data from the literature. Data collection started with corporate web pages and materials. This search provided us with basic data about companies and their management models. The next step was the keyword search in EBSCO database. We searched for two fundamental keywords - the name of the company and the name of the company together with the word management. This search provided us with research papers on chosen companies. The third step was the Google search that allowed us to collect data about companies from professional journals and blogs.

The organization of the paper is the following: Chapter 2 explains what the management model is and how management models changed in the 21st century. Chapter 3 introduces three organizations and their management models. Chapter 4 searches for similarities of discussed management models. Chapter 5 raises whether three organizations use their unusual innovative model.

\section{Management model}

The management model of the organization is the choices made by a company's top executives regarding how they define objectives, motivate effort, coordinate activities, and allocate resources; in other words, how they define the work of management (Birkinshaw and Goddard 2009).

The emergence of new organizational forms (and management models) is a co-evolutionary process at the intersection of managerial actions, institutional influences, and environmental phenomena (Dijksterhuis et al. 1999). So even though some organizations choose traditional management models based on hierarchy and bureaucracy, many of them search for different management models, as the traditional ones do not address their needs or trends of the digitalized and globalized world, as mentioned by Lee and Edmondson (2017). Less radical new approaches try to combine traditional with new, for example, a fluid (hypertext) organization (Nonaka and Takeuchi 1995) or spaghetti organization (Foss 2003); more radical approaches like holacracy (Robertson 2015), adhocracy (Waterman 1993), lattice organization 
(Grønning 2016) or requisite organization (Jaques 1989) come with revolutionary ideas on how to manage the organization.

In our paper, we discuss a radical approach to the management model in three organizations. W. L. Gore \& Associates (lattice organization), Zappos (holacracy), and Spotify (Spotify model).

\section{W. L. Gore \& Associates, Zappos, and Spotify, companies with unusual management models}

W. L. Gore \& Associates (Gore), Zappos, and Spotify management models were introduced to meet three requirements of today's business environment, as stated by Lee and Edmondson (2017). All three companies work in a fast-changing, technically demanding environment and, as such, are dependent on knowledge work. W. L. Gore \& Associates has made its name by creating innovative, technology-driven solutions, for medical devices that treat aneurysms to high-performance GORE-TEX fabrics. A privately held company whose annual sales exceed $\$ 2.5$ billion, Gore is committed to perpetuating its more than 50-year product innovation tradition. Today, the company claims a manufacturing or sales presence in more than 80 countries, employs more than 9,000 associates, and sells thousands of high-performance products in diverse markets around the world (gore-tex.com n.d.). Zappos is an online shoestore. It was founded in 1999 as Shoesite.com. In 2009 Amazon acquired the company, and it became one of the best service companies in the USA with annual revenue of \$408.06 million in 2019. Spotify is a popular audio streaming subscription service, with an estimated 286 million users. All three companies tried to implement the management model that brings knowledge sharing, innovativeness, trust, and the pleasant, friendly working environment employees can identify themselves with to the company. Even though the objective is the same, management models that help to achieve it are very different.

W. L. Gore \& Associates management model is based on the so-called "lattice" structure that creates a team-based environment encouraging personal initiative and person-to-person communication among all "associates," as employees are known (gore-tex.com n.d.). Employees are self-directed, change their roles, and move laterally through the organization as necessary. All employees have shares of the company. The objective of this model is to limit barriers to creativity and empower employees with decision-making rights. This leads to business success and happy employees.

When Bill and Vieve Gore founded the company in 1958, in Newark, Delaware, the aim was to build an organization where inventive people could "have fun and make money." But they did it seriously. Bill Gore was greatly influenced by human relations school theorists Douglas McGregor (Theory X, Theory Y) and Abraham Maslow ("hierarchy of needs"), and emphasized the importance of purpose. In the case of Gore, this meant applying technology to have a meaningful impact on society. He also wanted to support human fulfillment, embodied in a set of principles and management practices designed to foster trust, initiative, and enable the emergence of natural leaders (Caulkin 2019).

The company boasts a non-hierarchical management structure with associates typically working in teams. Both teams and individuals are given particular responsibilities, but they are also encouraged to set up their own projects or to develop new ways of implementing existing practices better (Plimmer 2005). In Gore's "lattice organization", anyone can talk to anyone, and no one tells another what to do. Instead, new employees - all of whom become shareholders if they stay - are encouraged to navigate their way through the business 
(Caulkin 2019). They are given a sponsor when they join, but they are expected to choose their own after six months. Most decisions are made informally, with the lack of a formal structure, meaning that if anyone has a particular need, they can go direct and ask for it, rather than passing through a chain of people. The company keeps conflict to a minimum by being selective about whom it hires, pointing out that the flat management structure will not suit people who value status or authority. However, leaders are trained in how to handle discipline and under-performance (Plimmer 2005). The company does not punish mistakes.

The Gore approach helps people feel in control, and they are more likely to come up with new products or ideas that will help the company (Plimmer 2005). On the other hand, this approach requires much self-responsibility. The most successful associates are those who look to themselves on how they can make a difference. They can be successful if they build their network of collaboration with other associates, not just locally but also globally ( $\mathrm{Ng} 2012)$.

Zappos became famous due to holacracy, a specific management model they introduced in January 2014. The company explains the reasons that led them to this management model: "Zappos has always been focused on delivering exceptional customer service - we call it WOW service. To provide WOW service, it's important that every employee understands our customers' needs and has the ability to improve the customer experience whenever possible. As our company grew, we became slower to sense and respond to customer feedback because of the layers employees needed to go through to get things done. Holacracy is a tool that allows every employee to quickly surface and act on customer feedback, so we can continuously provide WOW service, regardless of the size of our company" (zapposinsights.com n.d.).

Holacracy is based on sociocracy, a century old concept that relies on a sort of Quaker meetinghouse decision-making system (Reingold 2016). Holacracy aims to organize a company around the work that needs to be done instead of around the people who do it. As a result, employees do not have job titles. They are typically assigned to several roles that have explicit expectations. Employees are part of multiple circles that each perform certain functions (McGregor 2020). It is a management model where traditional top-down reporting lines are replaced by work circles that operate next to and on top of each other. People do not have jobs; they have "roles". The system does not value seniority or the size of the budget (Reingold 2016).

In addition, there are no managers in the classically defined sense (McGregor 2020). The authority and decision-making rest with the team that is actually doing the work, not with the boss. The teams are united by a strong vision set by a lean executive that steps out of as many decisions as possible (Powell 2015). "Lead links" have the ability to assign employees to roles or remove them from them but are not in a position to actually tell people what to do. Decisions about what each role entails and how various teams should function are instead made by a governing process run by people from each circle (McGregor 2020). Employees spend their work hours getting work done instead of seeking management approval for every small change in direction. It means that sometimes a chief executive will not be sure of the decisions made by their staff. It also means that one day you might be in charge of what someone else does, and the next day, they are in charge of you (Powell 2015).

There are no formal performance evaluations (Reingold 2016). Zappos addressed this problem by paying for skills employees had or obtained. Every circle had a certain number of "people points" that together approximate the scope of work. Zappos workers have 100 points 
each and must distribute them among their circles. If they do not enjoy their circles or feel they are not doing a good job-or if, as some employees report, lead links do not approve as many points as they need - they must find a new circle (Reingold 2016).

“A key part of Spotify's success is driven by the company's unique approach to organizing around work to enhance team agility. Spotify model focuses on how businesses can structure an organization to enable agility" (atlassian.com 2020). Spotify management model is made of so-called squads, tribes, chapters, guilds, and trios. "Squads are cross-functional, autonomous teams (typically 6-12 individuals) that focus on one feature area" (blog.crisp.se 2012) and are the main producer of value. Squads are supported by a product owner and an agile coach (Bäcklander 2019). "Each squad has a unique mission that guides the work they do, an agile coach for support, and a product owner for guidance. When multiple squads coordinate within each other on the same feature area, they form a tribe. Tribes consist of 40150 people. Chapters are the family that each specialist has, helping to keep engineering standards in place across a discipline. Chapters are typically led by a senior technology lead, who may also be the manager for the team members in that chapter. Team members who are passionate about a topic can form a guild, which essentially is a community of interest. The trio (aka TPD Trio) is a combination of a tribe lead, product lead, and design lead. Each tribe has a trio in place to ensure there is continuous alignment between these three perspectives when working on feature areas. Alliances are a combination of tribe trios (typically three or more) that work together to help their tribes collaborate on a bigger goal than anyone's tribe" (atlassian.com 2020).

The Spotify management model can be seen as a specific matrix. The vertical dimension is made of stable squads, where people with different skills collaborate. "The horizontal dimension is for sharing knowledge, tools, and code. The job of the chapter lead is to facilitate and support this. In matrix terms, think of the vertical dimension as "what" and the horizontal dimension as "how" (blog.crisp.se 2012).

Though the Spotify management model may look complicated, it introduces to the organization less formal processes and approaches. Teams are more independent and autonomous, and stress is put on self-management and self-control. Employees are entrusted to make their own decisions. The model also increases transparency, builds a culture of trust, and rapid learning. "In addition, they aim to constantly improve the organization, all the while attempting to be neither bogged down by bureaucracy nor torn apart by "too autonomous" teams" (Bäcklander 2019, p. 44).

\section{Some similarities}

Although every discussed company uses a different management model, similarities can be found.

The first similarity is a strong leader. Neither of the discussed management models developed naturally. In all three companies, the decision on the management system and its implementation were made and supported by a person with strong authority. W. L. Gore \& Associates owners and CEO Bill and Vieve Gore intentionally created the management model of their company on principles of McGregor's theory Y (McGregor 1960, Caulkin 2019). In Zappos, it was Tony Hsieh, who ran Zappos for 16 years and was the person who insisted that the company adopts holacracy (Gelles 2015). Spotify management model is linked with the names of Henrik Kniberg and Anders Ivarsson (Kniberg and Ivarsson 2012), who created and introduced its foundations. 
$\mathrm{Ng}$ (2012), who writes about Gore experience, stresses that without a strong leader, his vision and competence, and support, the change to the unusual management model will not be possible. A strong leader is important as innovation requires collaboration since innovators need inputs from the manufacturing, sales, and support functions to make their ideas become a reality. The role of a leader is to make sure all of them are working well together and are focused on the greatest opportunity ( $\mathrm{Ng} 2012)$.

The second similarity is that discussed companies and their unusual management models are not for everyone. The major challenge for all three organizations is people. Bill and Vieve Gore started W. L. Gore \& Associates in the basement of their home in 1958 and then slowly developed it on principles they supported; today, the company has over 11,000 employees (gore.com n.d.). Gore \& Associates is careful about whom "it hires, and those hires end up being a fraction of a percentage of applicants. As one Gore associate explained: "Gore is not for everyone. Our process for finding the right talent involves a certain degree of selfselection, which means we want job applicants to have enough information to decide that a career at Gore may not be the right fit after all"(Hamel and Spence 2010, p. 6). Gore even created the questionnaire for potential employees so that they could decide whether they may fit into their management model and culture or no.

The transformation in Zappos began in 2014, and employees describe it as weird, painful, and slow at first. They also complained about endless meetings that took them away from actual work. Finally, Mr. Hsieh sent a 4,700-word email to the entire company with an ultimatum: Embrace Holacracy or accept a buyout. The financial terms were generous, and 210 employees, or some 14 percent of the work-force, took the offer (Gelles 2015). Zappos is also cautious about employee fit. As T. Hsieh said: "We've actually passed on a lot of really smart, talented people that we know can make an immediate impact on our top or bottom line, but if they're not good for the company culture, we won't hire them for that reason alone" (Zippia.com n.d.).

Spotify initially started with scrum methodology when they had fewer employees, but when they started to grow, they thought of scaling; thus, they started utilizing agile scaling in their way (Mishra 2020). The fact that people were used to scrum methodology helped the implementation of the new model. Still, the company is facing, as they call it, "a hypergrowth," so one of their challenges is finding the right people among these interested in the company. Or, as Singel (2020) writes, "just because you have more fish, it doesn't necessarily mean they are the right fish." The company is actively searching for proper employees (they call them talents). Talents are supposed to complete another year with their current employer and explore what their options are. Then the decision is made (Singel 2020).

The third similarity is problems with implementation. The process of developing an unusual management model turned out not to be simple in all three organizations. In Gore, as Caulkin (2019) writes, there have also been uncomfortable moments when the company has struggled to reconcile the founding principles with the need for more structure to support growth.

A senior HR manager of Zappos who finally got used to holacracy stated that "employees were shocked and frustrated by the numerous mandates, the endless meetings, and the confusion about who did what. I hated all of it, in particular, because it was off-the-shelf, so focused on the rules of the game, and it explicitly felt icky without a focus on the people" (Reingold 2016). And as already mentioned, the frustration with holacracy led to $14 \%$ of 
employees leaving. After many employees left, Mr. Hsieh acknowledged that some of the remaining staff members wanted him to resign from the company he built (Geles 2015).

In Spotify the implementation discovered the problem of trust. Some agile coaches failed to help employees as they did not have technical capabilities, which caused misunderstandings. Some employees did not understand interrelations among individual parts of the system at all (Sundén 2017).

\section{Ambition or reality?}

All three companies introduced their innovative management models to support communication and knowledge sharing among employees, innovativeness and flexibility (Plimmer 2005; zapposinsights.com n.d.; atlassian.com 2020). Even though most literature states that the management models are successful, some publications indicate that Zappos left holacracy (Coporate-rebels.com 2016, Groth 2020), and Spotify never fully implemented their model (Agility11.com 2020, Lee 2020).

Out of the three discussed organizations, only the Gore management model seems to prove its sustainability. The reason lies probably in the fact that it reflects the founders' life philosophy; the company was built like that, and employees were carefully chosen to match the model from the beginning. As Mr. Field, a long-term employee, says: "We talk about the sweet spot where personal interest, skills and experience, and business needs intersect. Where that happens, we really encourage associates to chase those experiences." This, he believes, supplies the fun, the energy for forward momentum, and the fuel for Gore's creativity (Caulkin 2019).

Zappos first problems with holacracy were identified by S. Denning (2015), who expressed his doubts about the success of holacracy in Zappos (Denning 2015). He raises an important question concerning people who could not cope with holacracy and left Zappos. He asks: "Was it the best staff or the worst? Was it necessary?" (Denning 2015). He also questions the progressivity of holacracy because of the autocracy of circles which are run according to detailed procedures whose arrangement is vertical. "Each higher circle tells its lower circle (or circles), what its purpose is and what is expected of it. It can do anything to the lower circlechange it, re-staff it, abolish it-if it doesn't perform according to the higher circle's expectations" (Denning 2015). Finally, he sees a problem in the explicitness of holacracy that leads to endless discussions and communication, and he also questions empowerment in the company: "What empowerment it is when senior manager orders employees how to work" (Denning 2015). This all together with a hidden frustration of employees, leads him to conclusions that holacracy may not be the best management model for Zappos.

Coporate-rebels.com (2016) analyzed the situation in Zappos, and they also discovered that employees are frustrated with holacracy and wait and hope that the management model will be changed. Most of the long-time Zappos employees were fighting to protect the previous culture from being kidnapped by holacracy's processes and procedures. Employees were complaining that holacracy benefits for innovation are unclear and that it is an inconvenient management model for some teams. They also mentioned that "more and more teams find ways to beat the system and have adjusted the processes in such a way that they feel more comfortable with it" (coporate-rebels.com 2016). Coporate-rebels.com (2016) concludes that they think that a predefined and off-the-shelf system like holacracy replaces a proper dialogue between employees and hope, that loyalty of employees will be strong enough to overcome this, for them, frustrating holacracy period (Coporate-rebels.com 2016). 
Moreover, finally, Groth (2020) writes that "in the last few years, Zappos has been quietly moving away from holacracy. Zappos abandoned their at-times rigidly (and ironically) bureaucratic meetings and brought back managers, while retaining its circular hierarchy, a key artifact of holacracy. Zappos executive John Bunch, who co-led the rollout of holacracy, has explained that the company, famous for its exceptional customer service, encountered some "big challenges" in its business metrics and sought to redirect employees' focus back to the customer (an often cited criticism of holacracy is that it is too internally focused). By March 2017, the e-retailer had shifted its strategy to remedy this" (Groth 2020).

There are also indications that Spotify management model is not as successful as generally perceived. Agility11.com (2020) writes that Spotify doesn't use the 'Spotify Model'. In fact, it never truly did. They give four reasons why the model failed. First, re-labeling teams and departments as 'squads' and 'tribes' created confusion and failed mythology. Chapters were just functional areas with their own people manager, squads a cross-functional teams, and tribes were departments. Second, matrix management was ineffective. Any disagreement within the team often had to be resolved between multiple managers, and without consensus, then had to be escalated to the Director of the 'Tribe' (Department). Third, teams optimized for autonomy were not consistent. It led to duplications and complexity. Fourth, in alignment with the autonomy, Spotify gave each team control over its own process and practices. But they didn't have enough coaches to help every team, and many teams did not have enough knowledge of Agile principles and practices to implement them effectively (Agility11.com 2020).

Lee (2020), a former Spotify employee, writes that he discovered that the famed squad model was only ever aspirational and never fully implemented. He witnessed organizational chaos as the company's leaders incrementally transitioned to more traditional management structures. He quotes Sundén (2017), an agile coach in Spotify, who said: "Even at the time we wrote it, we weren't doing it. It was part ambition, part approximation." And warned companies from trying to copy the Spotify model. Lee (2020) sees the reason for model failure in the fast growth of Spotify. The startup model failed to adapt to the bigger complexity of the big organization (Lee 2020).

Michou (2020) also thinks that Spotify is not using the model anymore, and it failed (developed to something different). In his opinion, there are a few reasons why this happened. Engineering managers could not fully manage other people within the teams, which threatened delivery as none was accountable. There were vain and lengthy negotiations when engineering teams did not agree with one another. "With the growth of the teams' size, Spotify did not determine a common act for cross-team collaboration. Moreover, each team had a unique way of working; they did not have any guidelines on which they could choose. Hence, these aspects have brought a bad impact on the productivity of the whole organization. Spotify allowed teams to control their way of working. Therefore, many people did not understand the basis of Agile practices“ (Michou 2020).

\section{Conclusion}

The example of three organizations shows that it is not easy to create a management model that addresses three groups of trends mentioned by Lee and Edmondson (2017). All three companies tried to develop an environment that would allow them to respond quickly, manage knowledge work and knowledge sharing, and create a meaningful friendly environment. It shows that only W. L. Gore \& Associates managed to achieve this in the longterm perspective. Even though Zappos and Spotify management models are presented in the 
literature as example models and copied by other companies, Zappos and Spotify failed to implement them. Zappos was trying to solve the problem with growth leading to increased complexity by implementing holacracy (Coporate-rebels.com 2016), but their attempt resulted in even more increased complexity and failed. "Spotify chose the model where the model's key cultural elements need to be in place to allow the structure to thrive, such as trust and autonomy. If an organization does not shift its behaviors (and ultimately its culture), the benefits of the Spotify model will never be realized. If you simply rename teams to Squads, you do not change them" (atlassian.com 2020). And it is what exactly happened to Spotify themselves.

\section{References}

[1] AGILITY11.COM, 2020. Spotify Doesn't Use the Spotify Model. [online] Available at: https://www.agility11.com/blog/2020/6/22/spotify-doesnt-use-the-spotify-model/ (Accessed: 4 December 2020).

[2] ATLASSIAN.COM n.d.. Discover the Spotify model. [online] Available at: www.atlassian.com/agile/agile-at-scale/spotify/ (Accessed: 5 November 2020).

[3] BÄCKLANDER, G., 2019. Doing complexity leadership theory: How agile coaches at Spotify practise enabling leadership. Creativity and Innovation Management, 28(1), 4260.

[4] BIRKINSHAW, J. and J. GODDARD, 2009. What is your management model?. MIT Sloan Management Review, 50(2), 81.

[5] CAULKIN, S., 2019. WL Gore: the company others try and fail to imitate. FT.com; London [online] Available at: https://search-proquestcom.zdroje.vse.cz/docview/2268007114?pq-origsite=summon/ (Accessed: 26. November 2020).

[6] CORPORATE-REBELS.COM, 2016. An Inside View of Zappos (and the Mysterious Holacracy Experiment). [online] Available at: https://corporate-rebels.com/zappos/ (Accessed:4 December 2020).

[7] DENNING, S., 2015. Is Holacracy Succeeding At Zappos? Forbes. May 23, 2015. [online] Available at: https://www.forbes.com/sites/stevedenning/2015/05/23/isholacracy-succeeding-at-zappos/?sh=6ace28de56dc/ (Accessed: 4 December 2020).

[8] DIJKSTERHUIS, M. S., F. A. VAN DEN BOSH and H. W. VOLBERDA, 1999. Where do new organizational forms come from? Management logics as a source of coevolution. Organization Science, 10(5), 569-582.

[9] FOSS, N. J., 2003. Selective intervention and internal hybrids: Interpreting and learning from the rise and decline of the Oticon spaghetti organization. Organization Science, 14(3), 331-349.

[10] GELLES, D., 2015. At Zappos, Pushing Shoes and Visions. The New York Times. JULY 17, [online] Available at: https://www.nytimes.com/2015/07/19/business/at-zapposselling-shoes-and-a-vision.html/ (Accessed: 3 December 2020).

[11] GORE.COM n.d.. Overview. [online] Available at: www.gore.com/about/the-gore-story/. (Accessed: 3 December 2020).

[12] GORE-TEX.COM n.d.. Company Profile W.L. Gore \& Associates | GORE-TEX Brand. [online] Available at: https://www.gore-tex.com/pressroom/press-release/aboutgore/company-profile-wl-gore-associates. (Accessed: 26 November 2020). 
[13] GRØNNING, T., 2016. Working Without a Boss: Lattice Organization With Direct Person-to-Person Communication at WL Gore \& Associates, Inc. SAGE Publications: SAGE Business Cases Originals.

[14] GROTH, A., 2020. Zappos has quietly backed away from holacracy. Yahoo!Finance. 29.1.2020. [online] Available at: https://finance.yahoo.com/news/zappos-quietly-backedaway-holacracy-

090102533.html?guccounter=1\&guce_referrer=aHR0cHM6Ly93d3cuZ29vZ2x1LmNvbS 8\&guce_referrer_sig=AQAAAG21BAzakK2droqjaOf8aKTtKZmxTXaQydb75t2VA4bR mGxLQQutpucHCOuOee8ZCiF78RSRQoIEsnOApmwB1kurheXxOfYXkfds6fhog2kB S2EH41WGghzhsBj5XX3f7bikChq89-vnyd_-uLAuF01igJO5te1Sp4snicpXvuld/ (Accessed: 3 December 2020).

[15] HAMEL, G. and S. SPENCE, 2010. Innovation democracy: WL Gore's original management model. Management Innovation Exchange. [online] Available at: https://www.managementexchange.com/story/innovation-democracy-wl-gores-originalmanagement-model (Accessed 3 December 2020).

[16] JAQUES, E., 1989. Requisite organization: The CEO's guide to creative structure and leadership. Arlington, VA: Cason Hall.

[17] KNIBERG, H. and A. IVARSSON, 2012. Scaling Agile@ Spotify with Tribes, Squads, Chapters \& Guilds. [online] Available at: https://blog.crisp.se/wpcontent/uploads/2012/11/SpotifyScaling.pdf/ (Accessed 2 December 2020).

[18] LEE, J., 2020. Failed\#SquadGoals. Spotify doesn't use “the Spotify model"and neither should you. Sunday. 19.4.2020. [online] Available at: https://www.jeremiahlee.com/posts/failed-squad-goals/ (Accessed 3 December 2020).

[19] LEE, M. Y. and A. C. EDMONDSON, 2017. Self-managing organizations: Exploring the limits of less-hierarchical organising. Research in organizational behavior, 37. 35-58.

[20] McGREGOR, D., 1960. The human side of enterprise. New York: Mcgraw-Hill.

[21] McGREGOR, J., 2014. 'Zappos drops bureaucracy for "holacracy", Washington Post, 2014April. Available at: http://search.ebscohost.com.zdroje.vse.cz:2048/login.aspx?direct=true \&db=bwh\&AN=w apo.d9991830-74b8-11e3-8def-a33011492df2\&lang=cs\&site=ehost-live\&scope=site/ (Accessed: 2 December 2020).

[22] MICHOU, R., 2020. The Spotify Squad Model: Why did it Fail? 6.8.2020. [online] Available at: https://blog.aycoo.com/the-spotify-squad-model-why-did-it-fail/ (Accessed 4 December 2020).

[23] MISHRA, A., 2020. Spotify Scaling Agile Model. PM Today, 2.7.2020. [online] Available at: https://www.pmtoday.co.uk/spotify-scaling-agile-model/ (Accessed 4 December 2020).

[24] NG, E., 2012. Engineering corporate creativity As head of Gore-Tex maker WL Gore, Terri Kelly tries to foster innovation while making sure staff focus on the practicalities. South China Morning Post ; Hong Kong, 28 July 2012: 4.

[25] NONAKA, I. and H. TAKEUCHI, 1995. The knowledge-creating company: How Japanese companies create the dynamics of innovation. Oxford university press.

[26] PLIMMER, G., 2005. Theory $Y$ is the clear winner PROFILE WL GORE ASSOCIATES. Financial Times ; London (UK) [London (UK)]28 Apr 2005: 9. 
[27] POWELL, R., 2015. 'How companies from Zappos to Canva swap hierarchies for holacracy'. $B R W, \quad$ p. $3 . \quad$ [online] Available at: http://search.ebscohost.com.zdroje.vse.cz:2048/login.aspx?direct=true \&db=bsu\&AN=10 9289759\&lang $=$ cs\&site $=$ ehost-live \&scope $=$ site (Accessed: 27 November 2020).

[28] REINGOLD, J., 2016. 'The Zappos Experiment', Fortune, 173(4), pp. 206-214. Available at: http://search.ebscohost.com.zdroje.vse.cz:2048/login.aspx?direct=true\&db=bth\&AN=11 3500241\&lang=cs\&site=ehost-live\&scope=site/ (Accessed: 27 November 2020).

[29] ROBERTSON, B. J., 2015. Holacracy: The new management system for a rapidly changing world. Henry Holt and Company.

[30] SINGEL J. (2020). Talent Acquisition in Times of Turmoil. Posted on May 13, 2020 [online] Available at: https://hrblog.spotify.com/2020/05/13/talent-acquisition-in-timesof-turmoil/ (Accessed: 3 December 2020).

[31] SUNDÉN, J., 2017. You can do it BETTER then the Spotify model. Lean Agile Scotland. 2017. [online] Available at: https://vimeo.com/240125835 (Accessed: 4 December 2020).

[32] WATERMAN, R. H., 1993. Adhocracy. WW Norton \& Company

[33] ZAPPOS.COM n.d. Holacracy and self-organization. [online] Available at: https://www.zapposinsights.com/about/holacracy. (Accessed: 14 December 2020)

[34] ZIPPIA.COM n.d.. Zappos - Hiring for Culture and the Bizarre Things They Do. [online] Available at: https://www.zippia.com/employer/zappos-hiring-for-culture-andthe-bizarre-things-they-do/. (Accessed 14. December 2020). 